\title{
Perineal Decubitus Ulcer with Urethro-cutaneous Fistula without Bilateral Ischiectomy: Case Report
}

Sai S. Ramasastry, M.D., F.R.C.S.E., ${ }^{1}$ Mark S. Granick, M.D. ${ }^{1}$ and Frederick S. Schwentker, M.D., F.A.C.S. ${ }^{2}$

${ }^{1}$ Division of Plastic and Reconstructive Surgery and ${ }^{2}$ Urology, 1117 Scaife Hall, University of Pittsburgh, Pittsburgh, PA 15261, U.S.A.

\section{Summary}

Perineal decubitus ulcer with urethro-cutaneous fistula has previously been reported in paraplegics as a late complication following bilateral ischiectomy. This case report illustrates the occurrence of the problem in a male paraplegic without bilateral ischiectomy, and this has not been previously reported in the English literature. Successful reconstruction was accomplished with a full thickness skin graft tube and and gracilis muscle flap.

Key words: urethro-cutaneous fistula; perineal decubitus ulcer.

Perineal decubitus ulcers with urethro-cutaneous fistula are uncommon but can occur as a complication of total ischiectomy in paraplegic patients (Commar and Gors, 1958; Karaca et al., 1978). These lesions have previously been treated by conservative wound management or by local flaps and urinary diversion. To our knowledge such a problem without bilateral ischiectomy has not been previously described in the English literature. In the case described here, the patient developed a decubitus ulcer of the perineum with a urethro-cutaneous fistula following conservative management of his bilateral ischial ulcers without undergoing bilateral ischiectomy.

\section{Case report}

A 36 year old male patient paralysed below $T_{12}$ for 14 years following a gunshot injury of his spine developed a perineal decubitus ulcer with a urethro-cutaneous fistula. The patient had previously undergone conservative treatment of his ischial and trochanteric pressure sores on numerous occasions without ischiectomy. On admission, the patient was noted to have bilateral $4 \times 5 \mathrm{~cm}$ superficial ischial and trochanteric decubitii. Also $3.5 \times 4 \mathrm{~cm}$ perineal decubitus ulcer with a $4.5 \mathrm{~cm}$ gap in the perineal urethra with a urethro-cutaneous fistula (Fig. 1). A 


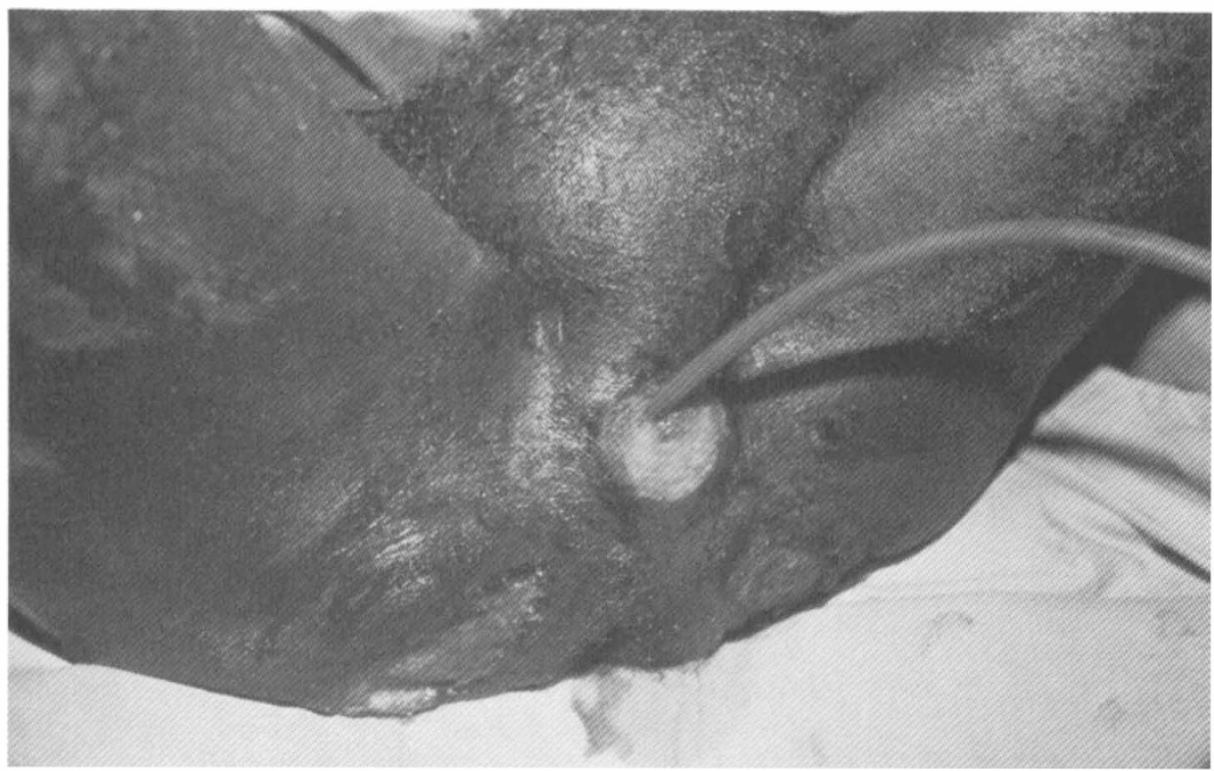

Figure 1 Perineal decubitus ulcer with a urethro-cutaneous fistula, not responsive to urinary diversion. Note the catheters at the fistula site.

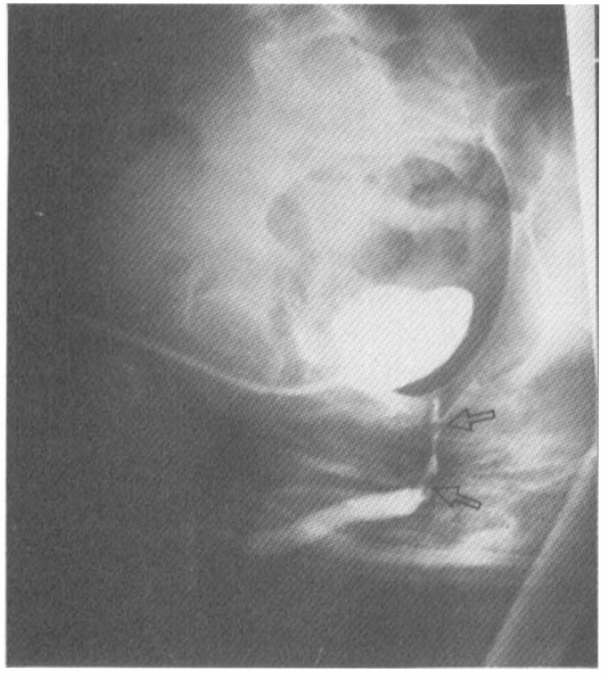

Figure 2 Cysto-urethrogram demonstrating a low capacity spastic bladder with structure of the membraneous urethra and urethro-cutaneous fistula.

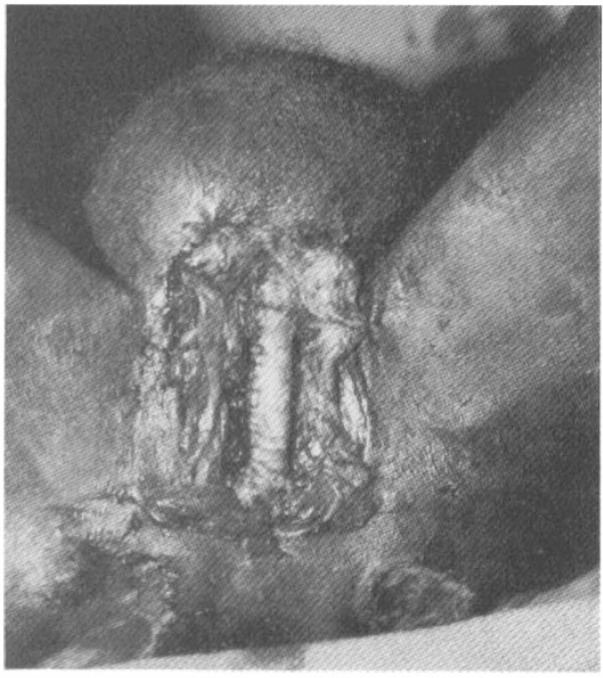

Figure 3 Full thickness urethral tube reconstruction.

pre-operative cysto-urethrogram revealed a low capacity spastic bladder with a stricture of the membraneous urethra, which was incised and dilated (Fig. 2). A suprapubic cystostomy to divert the urinary stream failed to heal the fistula. The urethral fistula was repaired with a full thickness skin graft tube (Fig. 3) and buttressed with a gracilis muscle pedicle flap and covered with meshed split 


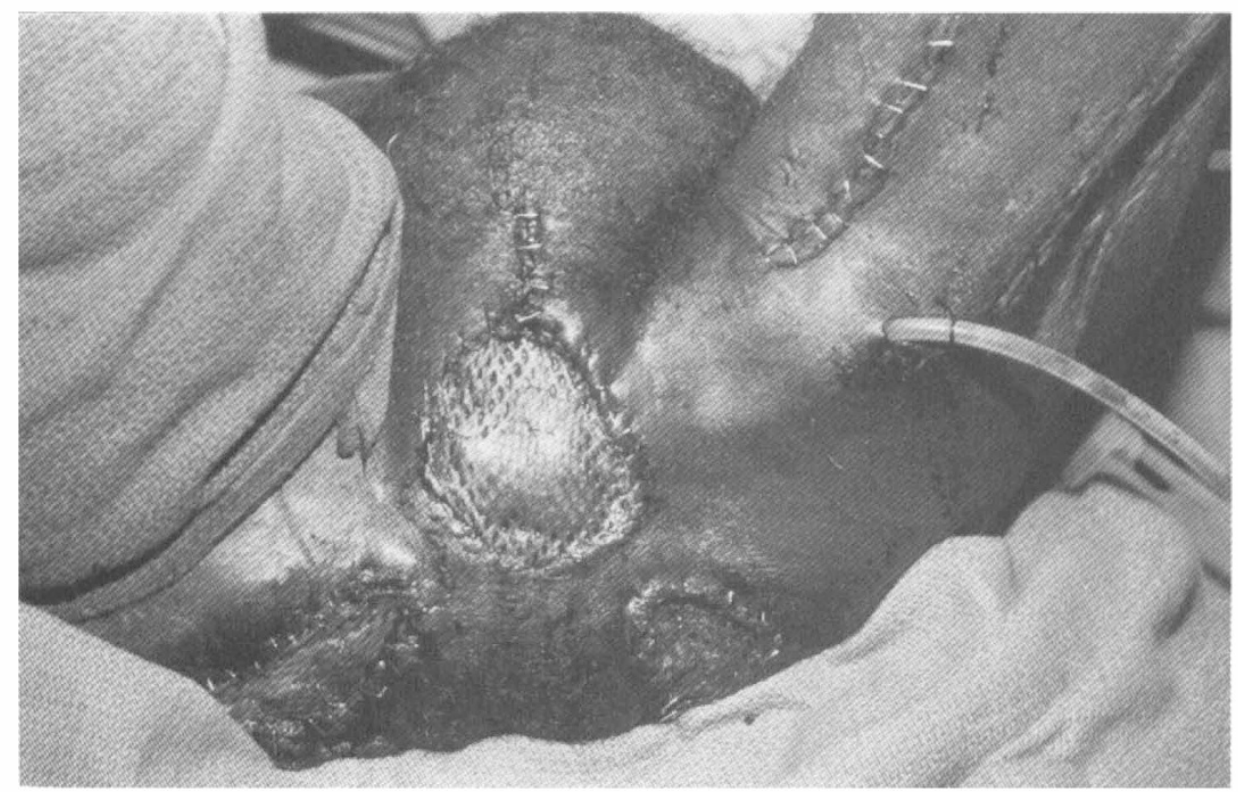

Figure 4 Gracilis muscle covered with a meshed split-thickness skin graft.

thickness skin graft (Fig. 4). The ischial and trochanteric ulcers were skin grafted. All the skin grafts initially did well until the eleventh postoperative day when they were completely lost due to poor patient compliance, even though a Clinitron bed had been instituted pre- and postoperatively. These areas were successfully regrafted. A cysto-urethrogram 3 weeks postoperatively showed a patent urethral reconstruction without leakage. The patient, however, refused to keep the suprapubic catheter clamped. Eleven months after operation the patient has recurrence of the ischial ducubitus ulcers due to poor patient compliance, but the urethral reconstruction remains stable without perineal breakdown or recurrence of the urethro-cutaneous fistula.

\section{Discussion}

Perineal decubitus ulcers are rarely seen except in the unusual situation where a paraplegic patient has had total ischiectomies for ulcers. Large perineal wounds, on the other hand, are often seen following proctocolectomy for granulomatous colonic disease or after oncologic resections. In the case described the patient had conservative treatment for his bilateral ischial ulcers and had not undergone ischiectomy. The perineal urethro-cutaneous fistula probably occurred as a result of the erosion of the floor of the urethra from poor self care by the patient in managing his perineal decubitus.

Perineal urethro-cutaneous fistulae are usually either congenital or iatrogenic. The literature abounds with descriptions of local skin and muscle flaps reconstruction of these fistulae, usually in association with surgery for epispadias or hypospadias. Iliac loop diversion has occasionally been used in the management of the difficult urethro-cutaneous fistula (Karaca et al., 1978). The gracilis 
muscle was selected in this patient because of its size, proximity to the lesion, reliability, ease of dissection and, its easy accessibility without position change (Labandter, 1980). The well-vascularised muscle flap served as the bed for a tubed full-thickness skin graft urethral reconstruction (Benatar and Brzezinski, 1984). The urethra remained patent even after the patient removed his Foley catheter three weeks postoperatively and refused to void transurethrally, preferring his suprapubic cystotomy catheter for bladder decompression.

\section{References}

BenAtAR D, BRZEZINSKI A 1984 The use of full thickness skin grafts in the reconstruction of the male urethra. Annals of Plastic Surgery 13:431-435.

Commar AE, Gors E 1958 Perineal urethral diverticulua-Complications of removal of ischium. Journal of American Medical Association 168:2000-2003.

Karaca AR, Binns AJ, Blumenthal FS 1978 Complications of total ischiectomy for the treatment of ischial pressure sores. Plastic and Reconstructive Surgery 62:96-99.

LABANDTER HP 1980 The gracilis muscle flap and musculocutaneous flap in the repair of perineal and ischial defects. British Journal of Plastic Surgery 33:95-98 